\title{
A field study of the ventilatory response to ambient temperature and pressure in sport diving
}

\author{
F L L Muller \\ Department of Oceanography, The University, Southampton, UK
}

\begin{abstract}
This study reports on the relationship between minute ventilation $\left(\dot{\mathrm{V}}_{\mathrm{E}}\right)$ and environmental variables of temperature $(T)$ and pressure $(P)$ during open water diving. The author conducted a total of 38 dives involving either a light $(20$ dives) or a moderate (18 dives) level of physical activity. Within each of these groups, $P$ and $T$ taken together accounted for about two thirds of the variance in the $\dot{V}_{E}$ data. A very significant increase in $\dot{\mathrm{V}}_{\mathrm{E}}$ was observed as $T$ decreased $\left(1<\mathrm{T}\left({ }^{\circ} \mathrm{C}\right)<22\right)$, and the magnitude of this increase at a given pressure level was similar in the 'light' and the 'moderate' data sets. A second order observation, particularly notable at lower temperature, was the decrease in $\dot{V}_{E}$ with increasing pressure under conditions of light work. Empirical functions of the form $\dot{V}_{E}=A+B / P$ $n[1+\exp (T-8) / 10]$, where $A, B$, and $n$ are adjustable variables, could accommodate both data sets over the whole range of $T$ and $P$. These results are the first obtained under actual diving conditions to provide evidence for interactions between $P, T$, and $\dot{V}_{E}$. Understanding the physiological mechanisms by which these interactions occur would assist in appreciation of the limitations imposed on scuba divers by the environmental conditions as they affect their ventilatory responses.

(Br J Sports Med 1995; 29 : 185-190)
\end{abstract}

Keywords: scuba diving; wet dives; ventilatory response to temperature; ventilatory response to pressure

Personal air endurance is not a factor usually taken into account explicitly by sport and scientific divers in dive planning. Yet the ability of divers to take full advantage of their air supply by planning a safe and appropriate dive profile (depth as a function of time) for the proposed task, as well as to adhere to it, depends in great measure on respiratory variables. Accordingly, the general aim of this study was to answer the following questions. (I) For a given subject, can we make a reasonably accurate prediction of the minute ventilation averaged during a dive, $\dot{\mathrm{V}}_{\mathrm{E}}$, based on anticipated mean water temperature $(\mathrm{T})$ and pressure (P)? (2) If so, how does exercise affect the form of the relationship giving $\dot{\mathrm{V}}_{\mathrm{E}}$ as a function of the explanatory variables $P$ and $T$ ? With these objectives in mind, I found it crucial to use the same subject and the same equipment, ${ }^{1-2}$ and to ensure that the apparent control of $\dot{V}_{\mathrm{E}}$ by the environmental variables $\mathrm{P}$ and $\mathrm{T}$ should be manifested over a wide range of conditions.

Address for correspondence: Dr F L L Muller, Department of Oceanography, The University, Southampton, SO17 1BJ, UK
The 'environmental conditions' simulated in most laboratory studies may be of limited relevance to sport diving. Experiments focusing on the effects of pressure have usually been performed within a compression chamber, with the subject either lying down ${ }^{3}$ or sitting on a chair or bicycle ergometer. ${ }^{4-7}$ Likewise, the effects of water temperature on respiratory variables have been investigated in relatively small tanks in which the subject was immersed up to the shoulders. ${ }^{8-10}$ Changes in $\dot{V}_{E}$ induced by breathing cold gas have also been reported ${ }^{11-13}$ but there is some uncertainty as to their relevance to open water situations, since sport divers in the field also exchange heat through their wet suits. ${ }^{914}$ Reports on the combined effects of pressure and temperature are fewer ${ }^{12}$ and are usually concerned with exposure to pressures much higher than those permitted by air diving techniques; consequently, the pressure range to which most scuba diving is limited (1-6 ATA) tends to be undersampled in such studies.

The results of a field based approach to the subject of ventilatory response to $P$ and $T$ are presented. An empirical analytic expression was fitted to the data, whereby $\mathrm{P}$ and $\mathrm{T}$ were regarded as independent explanatory variables.

\section{Methods}

The subject (the author) was a 30 year old sport diver with 10 years of diving experience ( $150 \mathrm{~h}$ using scuba) and extensive cold water experience. His height, weight, and vital capacity were $1.75 \mathrm{~m}, 61 \mathrm{~kg}$, and 5.3 litres, respectively. The diver wore a one piece $6.5 \mathrm{~mm}$ thick wetsuit and a $7 \mathrm{~kg}$ weight belt. Neutral buoyancy was provided by a horse collar type buoyancy compensator (Spirotechnique Atlantis), with a direct feed from a low pressure port of the regulator removing the need for oral inflation. The air was supplied from an aluminium tank (Dacor, 10.3 litre internal volume) via a two stage Spirotechnique PRO-RS regulator. A Suunto Solution dive computer was used to monitor depth; it was also interrogated after each dive to provide the full dive profile data from which mean depth and temperature were determined. The same neoprene wetsuit was used in all seasons, the only difference being that mittens were worn below $11^{\circ} \mathrm{C}$ to prevent potentially hazardous finger numbness; above $11^{\circ} \mathrm{C}$, gloves were sufficient to maintain a good degree of dexterity. The equipment used during the 'moderate work' dives also 
Table 1. Characteristics of the open water dives and related ventilation data

\begin{tabular}{|c|c|c|c|c|c|}
\hline $\begin{array}{l}\text { Duration } \\
\text { of dive } \\
\text { (min) }\end{array}$ & $\begin{array}{c}\text { Maximum } \\
\text { depth } \\
(m)\end{array}$ & $P(A T A)$ & $T\left({ }^{\circ} \mathrm{C}\right)$ & $\begin{array}{c}\text { Observed } \mathrm{Pr} \\
\dot{V}_{E} \\
\text { (litre } \cdot \min ^{-1}\end{array}$ & $\begin{array}{c}\text { Predicted } \\
\dot{V}_{E} \\
\left.{ }^{-1} B T P S\right)\end{array}$ \\
\hline \multicolumn{6}{|c|}{ Light work } \\
\hline 40 & 6 & 1.30 & 2.0 & 16.0 & 16.2 \\
\hline 30 & 14 & 2.00 & 2.5 & 17.2 & 15.3 \\
\hline 40 & 30 & 3.35 & 2.5 & 14.7 & 14.1 \\
\hline 48 & 6 & 1.30 & 3.0 & 16.4 & 16.0 \\
\hline 41 & 25 & 2.80 & 4.0 & 13.9 & 14.3 \\
\hline 35 & 34 & 3.20 & 5.0 & 12.5 & 14.0 \\
\hline 70 & 3 & 1.23 & 9.0 & 12.6 & 14.6 \\
\hline 60 & 10 & 1.55 & 10.0 & 14.9 & 14.0 \\
\hline 67 & 29 & 3.17 & 12.0 & 11.8 & 12.7 \\
\hline 52 & 22 & 2.50 & 12.5 & 13.5 & 12.9 \\
\hline 100 & 4 & 1.13 & 15.0 & 12.8 & 13.3 \\
\hline 60 & 7 & 1.40 & 16.0 & 12.6 & 12.8 \\
\hline 55 & 6 & 1.40 & 16.0 & 12.8 & 12.9 \\
\hline 90 & 3 & 1.15 & 16.5 & 13.8 & 12.9 \\
\hline 70 & 8 & 1.60 & 18.0 & 13.7 & 12.4 \\
\hline 50 & 23 & 2.35 & 19.0 & 13.9 & 11.9 \\
\hline 66 & 8 & 1.58 & 19.0 & 12.0 & 12.2 \\
\hline 63 & 10 & 1.68 & 20.0 & 10.4 & 12.0 \\
\hline 50 & 16 & 2.10 & 21.0 & 11.0 & 11.7 \\
\hline 48 & 14 & 1.83 & 21.0 & 11.8 & 11.8 \\
\hline \multicolumn{6}{|c|}{ Moderate work } \\
\hline 50 & 5 & 1.20 & 2.0 & 22.3 & 21.3 \\
\hline 37 & 28 & 3.24 & 2.0 & 19.7 & 20.4 \\
\hline 33 & 16 & 2.40 & 4.0 & 20.5 & 20.1 \\
\hline 44 & 30 & 3.43 & 4.5 & 20.2 & 19.7 \\
\hline 39 & 19 & 2.60 & 6.5 & 16.6 & 19.3 \\
\hline 45 & 24 & 3.00 & 9.5 & 18.4 & 18.4 \\
\hline 45 & 33 & 2.60 & 11.0 & 17.0 & 18.0 \\
\hline 72 & 17 & 2.32 & 13.0 & 19.0 & 17.5 \\
\hline 48 & 6 & 1.50 & 13.0 & 17.3 & 17.7 \\
\hline 75 & 4 & 1.20 & 13.5 & 18.9 & 17.7 \\
\hline 28 & 34 & 3.68 & 14.5 & 20.3 & 16.9 \\
\hline 60 & 20 & 2.70 & 15.0 & 16.2 & 16.9 \\
\hline 65 & 20 & 2.15 & 16.0 & 16.2 & 16.7 \\
\hline 55 & 14 & 2.00 & 16.0 & 17.5 & 16.8 \\
\hline 86 & 10 & 1.65 & 19.0 & 13.9 & 16.1 \\
\hline 50 & 6 & 1.42 & 19.0 & 16.0 & 16.1 \\
\hline 80 & 4 & 1.33 & 20.0 & 14.3 & 15.9 \\
\hline 37 & 11 & 1.68 & 21.0 & 17.7 & 15.6 \\
\hline
\end{tabular}

$\mathrm{P}$ and $\mathrm{T}$ denote mean pressure and temperature over the duration of the dive. The corresponding $\dot{V}_{E}$ integrates any fluctuations in $\mathrm{P}$ and $\mathrm{T}$ over that period

included a home made navigation console consisting of an aluminium triangular slate kept horizontal by holding two handles mounted under each side. A compasswhich allowed direct reading from an 'arms stretched' position-was mounted on top of the slate. The lower part of the instrument consisted of an aluminium tube welded to the stabilizing slate and holding a propeller driven odometer calibrated in metres.

All the dives took place at the same site, situated in the East Passage of Narragansett Bay, Rhode Island, USA. Depths of $30-40$ m could be found within $300 \mathrm{~m}$ of the entry/exit point on the shore. The dives were planned to coincide with slack high or low water: in this way, tidal currents did not interfere with the 'light work' protocol (see below), while it was possible to control the level of exercise in the 'moderate work' protocol by simply maintaining a constant cruising speed. Unless the mean operating depth was already shallower than $12 \mathrm{~m}$, this exercise level was kept up during ascent to $12 \mathrm{~m}$ ('ascent check depth') where a pause was made to read the pressure gauge and terminate the dive. A decision was then made on the remaining ascent procedure, either to return to the surface or to make appropriate decompression stops at 9,6 , or $3 \mathrm{~m}$.

The term 'light work' appearing in Table 1 corresponds to the minimum level of exertion required to explore the seabed while maintaining depth and posture control. Listed under this heading are exploratory dives, during which the diver simply 'bumped along the bottom' in a 'head down' position and made relatively little headway. The term 'moderate work' (Table 1) designates a group of dives whereby the diver was swimming with fins at a speed of approximately $1.9 \mathrm{~km} \cdot \mathrm{h}^{-1}(1.0 \mathrm{knot})$, while holding out the navigation console in front of him. There was a natural tendency for the diver to adopt a 'head down' position, resulting in a $\sim 30 \mathrm{~cm}$ hydrostatic pressure difference between the mouthpiece and the pressure centroid in the chest, ${ }^{1516}$ in the 'moderate work' as well as in the 'light work' dives.

Dive duration was defined as the time elapsed from first reaching the bottom (or the $12 \mathrm{~m}$ horizon for deeper dives) to terminating the dive at the ascent check depth. Mean pressure $(\mathrm{P})$ and temperature $(\mathrm{T})$ were obtained by averaging the readings taken by the computer every $3 \mathrm{~min}$ throughout the dive and scrolled out after the dive. $\dot{V}_{E}$ was determined from a knowledge of dive duration, ambient temperature, drop in tank pressure, and internal volume of the tank. As a first step, the mean rate of air consumption (litres $\cdot \mathrm{min}^{-1}$ ) was calculated at 1 ATA and ambient $T$. This value was then divided by $\mathrm{P}$ and multiplied by $\left(273+\mathrm{T}_{\mathrm{ex}}\right) /(273+\mathrm{T})$ to obtain an interpretable measure of $\dot{V}_{E}$, that is, corrected to body temperature and ambient pressure. ${ }^{17}$ The value of $T_{e x}$ used in this procedure was calculated from the formula ${ }^{14}: T_{e x}=24+0.32 \mathrm{~T}$, where $T_{e x}$ is the expired air temperature and $\mathrm{T}$ represents the ambient-and hence the inspired-air temperature.

\section{Statistical analyses}

In a field experiment of this kind, artefacts could be introduced if the explanatory variables $\mathrm{P}$ and $\mathrm{T}$ turned out to be correlated as a result of the experimental design. For example, such a correlation could stem from the impossibility of obtaining simultaneously high values of $P$ and $T$, since deeper waters $(P>3$ ATA) remained below $15^{\circ} \mathrm{C}$ all year round. Each data set was tested for independence between $\mathrm{P}$ and $\mathrm{T}$ by comparing the observed, $o_{i}$, and expected, $e_{i}$, frequency of samples in each of the following categories: $\mathrm{P}<2$ and $\mathrm{T}<10$; $\mathrm{P}<2$ and $\mathrm{T} \geqslant 10$; and $\mathrm{P} \geqslant 2$ and $\mathrm{T}<10 ; \mathrm{P} \geqslant 2$ and $\mathrm{T} \geqslant 10$. For both data sets, the statistic $\chi^{2}=$ $\Sigma\left(o_{i}-e_{i}\right)^{2} / e_{i}$ was less than the critical value of the $\chi^{2}$ distribution $\chi_{0.05}^{2}$ with $(2-1)(2-1)=1$ degree of freedom, so that the hypothesis of independence between $P$ and $T$ was accepted at the 0.05 level of significance.

The multifactor analysis of variance procedure ${ }^{18}$ was used to analyse the effects of $P, T$, and dive duration on the measured response $\dot{V}_{\mathrm{E}}$. In this procedure, three levels 
Table 2. Two factor analysis of the variance in $\dot{\mathrm{V}}_{\mathrm{E}}$ due to $\mathrm{P}$ and $\mathrm{T}$

\begin{tabular}{llrrr}
\hline & $\begin{array}{l}\text { Source of } \\
\text { variation }\end{array}$ & $\begin{array}{c}\text { Sum of } \\
\text { squares }\end{array}$ & Percent & $\begin{array}{c}\text { Significance } \\
\text { level }\end{array}$ \\
\hline Light work & & & & \\
& P & 13.3 & 18 & 0.016 \\
& T & 39.1 & 55 & 0.001 \\
& P and T & 48.6 & 69 & 0.002 \\
& P-T interaction & 6.0 & 9 & 0.030 \\
& Residual & 15.8 & 22 & \\
& Total (corr.) & 70.4 & 100 & \\
Moderate & & & & \\
work & & & & \\
& P & 5.8 & 6 & 0.553 \\
& T & 48.7 & 53 & 0.011 \\
& P and T & 53.5 & 59 & 0.037 \\
& P-T interaction & 7.8 & 8 & 0.487 \\
& Residual & 29.9 & 33 & \\
& Total (corr.) & 91.2 & 100 & \\
\hline
\end{tabular}

Note in the light work data set that both the main $\mathrm{P}$ effect and the P-T interaction effect are significant at the $5 \%$ level, whereas neither effect is significant in the moderate work data set

were defined for each factor, as follows. Factor 1 : $\mathrm{P}<1.5 ; 1.5 \leqslant \mathrm{P}<2.5 ; \mathrm{P} \geqslant 2.5$. Factor $2: \mathrm{T}<7.5$; $7.5 \leqslant \mathrm{~T}<17 ; \mathrm{T} \geqslant 17$. Factor 3 : $\mathrm{dd}<50 ; 50 \leqslant \mathrm{dd}$ $<70$; dd $>70$. Statistically significant effects and interactions were indicated at the 0.05 level if the value of the statistic used was less than a random variable having the $\mathrm{F}$ distribution. ${ }^{18}$ As expected, the duration of the dive had no influence on $\dot{V}_{E^{\prime}}$ so that the analysis was repeated with two factors only (Table 2). When this was done, it was found that $\mathrm{P}$ and $\mathrm{T}$ taken together accounted for $69 \%$ of the total variability in the $\dot{\mathrm{V}}_{\mathrm{E}}$ observations at light workload, and $59 \%$ at moderate workload (Table 2). It was therefore legitimate to proceed to the next step, that is, seek a relationship expressing the dependence of $\dot{V}_{\mathrm{E}}$ on $\mathrm{P}$ and $\mathrm{T}$.

In choosing the form of the response function $\dot{V}_{E}(P$, $\mathrm{T})$ the following needs were considered: (a) to fit the data as well as possible, using the least squares criterion; (b) to avoid over-parameterization; (c) to ensure that the parameters are interpretable in terms of their effect on the sensitivity of $\dot{V}_{E}$ to $P$ and $T$; (d) to account for the interaction existing between $P$ and $T$ at light workloads (see Table 1); and (e) to ensure that realistic extrapolations of $\dot{V}_{E}$ can still be obtained when using $P$ and $T$ values outside the range encompassed by the present data set.

\section{Results}

Since $T$ appears to exert the single largest influence on $\dot{\mathrm{V}}_{\mathrm{E}}$ (Table 2), it seems sensible to have ordered the data with temperature (Table 1), instead of chronologically. Although there is no available theoretical basis on which to select the function $\dot{V}_{E}(P, T)$, it was found that an empirical equation of the form

$$
\dot{\mathrm{V}}_{\mathrm{E}}=\mathrm{A}+\frac{\mathrm{B}}{\mathrm{P}^{\mathrm{n}}\left[1+\exp \left(\frac{\mathrm{T}-8}{10}\right)\right]}
$$

where $\mathrm{A}, \mathrm{B}$ and $\mathrm{n}$ are the adjustable parameters, could accommodate the data of each workload group over the
Table 3. Non-linear least squares estimates (SD) of the parameters defining the function $\dot{V}_{E}(P, T)$ and associated standard deviation of $\dot{V}_{E}$

\begin{tabular}{lcc}
\hline & Light work & Moderate work \\
\hline A & $10.0(0.8)$ & $13.0(1.5)$ \\
$\mathrm{B}$ & $10.6(2.4)$ & $13.1(4.4)$ \\
$\mathrm{n}$ & $0.40(0.16)$ & $0.11(0.19)$ \\
$\mathrm{SD}$ of $\dot{\mathrm{V}}_{\mathrm{E}}$ & 1.1 & 1.7 \\
\hline
\end{tabular}

The $P, T$, and $\dot{V}_{E}$ data used in the fitting procedure were expressed in $\mathrm{ATA},{ }^{\circ} \mathrm{C}$, and litres $\cdot \mathrm{min}^{-1}$, respectively

whole range of temperatures $\left(1<\mathrm{T}\left({ }^{\circ} \mathrm{C}\right)<22\right)$ and pressures $(1<\mathrm{P}(\mathrm{ATA})<4)$. It is evident that $\mathrm{A}$ represents the value of $\dot{V}_{E}$ when the denominator $\mathrm{P}^{n}$ $[1+\exp (T-8) / 10]$ is large, that is, at high water temperature. Indeed, one would expect $\dot{V}_{\mathrm{E}}$ to level off when thermoneutral conditions are approached, ${ }^{1014}$ and an examination of the data in Table 1 indicates that this is generally correct. The effect of decreasing temperature is then expressed by adding a second order term to the constant term $A$. In order to provide for the small negative correlation between $\dot{\mathrm{V}}_{\mathrm{E}}$ and $\mathrm{P}$ and for the interaction P-T (Tables 1 and 2), the temperature correction factor is multiplied by $\mathrm{P}^{\mathrm{n}}$, where the exponent $\mathrm{n}$ is significantly less than unity. To a first approximation, the parameters $\mathrm{n}$ and $\mathrm{B}$ give an indication of the sensitivity of $\dot{V}_{E}$ to $P$ and $T$ respectively. This empirical model was fitted to both sets of dives by non-linear least squares regression, to produce the values of the parameters shown in Table 3. As would be expected from the physical significance of the parameters, $\mathrm{A}$ is greater at moderate than at light work rate. The sensitivity of $\dot{V}_{E}$ to pressure-which manifests itself at lower temperatures through the exponent $n$-is only statistically significant at light work rates, which is consistent with the two factor analysis of variance presented earlier (Table 2). In other works, increasing the value of $P$ has no significant effect on $\dot{V}_{E}$ at moderate levels of exercise, but tends to lower $\vec{V}_{\mathrm{E}}$ when the exercise level is minimal and $\mathrm{T}$ is low (the latter condition stems from the fact that the second term in the expression of $\dot{V}_{E}$ reduces to zero at high values of $T$ ). Finally, there is no significant difference in the value of $B$ between the 'light' and 'moderate' data sets. This indicates that the dependence of $\dot{V}_{E}$ on T (at 1 ATA) is closely similar in both sets of dives.

The modelled dependence of $\dot{V}_{E}$ on $T$ (at constant $P$ ) and $P$ (at constant $T$ ) is illustrated for both sets of data in the top and centre graphs of Figure 1, respectively. The finding that $\dot{V}_{\mathrm{E}}$ and $\mathrm{P}$ are negatively correlated at light workload and low temperature is particularly interesting, as it rules out the possibility of one obvious experimental artefact: the expectation would be that wetsuit compression resulting from increasing pressure would lead to a loss of thermal insulation and thus exacerbate the effect of temperature; however, the reverse response is observed, suggesting a direct effect of $\mathrm{P}$ on $\dot{\mathrm{V}}_{\mathrm{E}}$, which more than counteracts the anticipated suit compression effect. Figure 1 shows that, on average, the value of $\dot{V}_{\mathrm{E}}$ increases by 5 litres $\cdot \mathrm{min}^{-1}$ in response to moderate levels of physical activity. On this basis, it is 

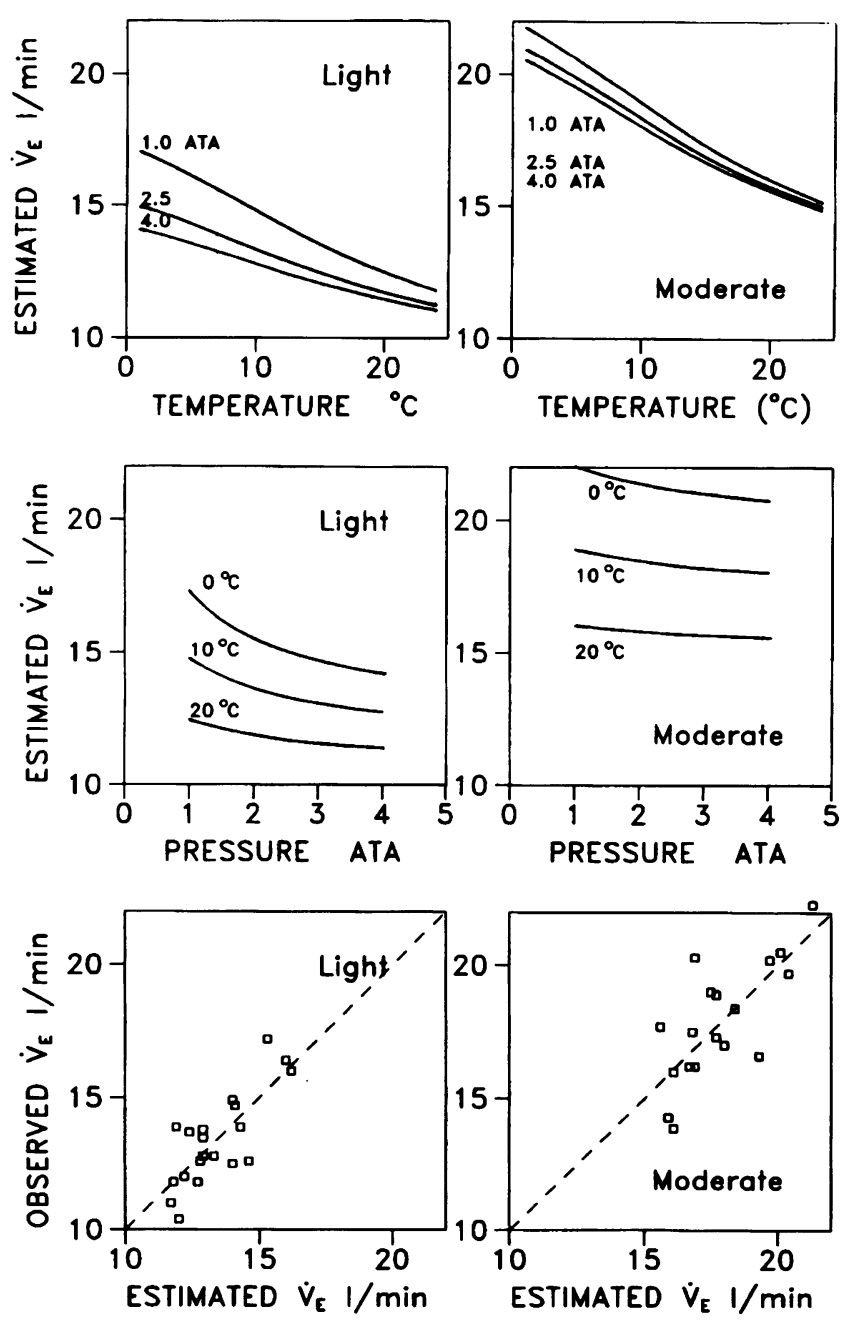

Figure 1. Ventilatory response to a diver to water temperature (top) and pressure (middle) under light (left) and moderate (right) workloads, as described by equation 1 . In the scatter plots (bottom), actual measurements of $\dot{V}_{\mathrm{E}}$ have been plotted against the fitted values

probable that a major part of the unaccounted variations in $\dot{V}_{\mathrm{E}}$ (light work, \pm 1.1 litre $\cdot \mathrm{min}^{-1}$; moderate work, \pm 1.7 litre $\cdot \mathrm{min}^{-1}$ ) is due to the lack of any quantitative information on the two work rates used, given the limiting conditions of field work.

\section{Discussion}

This study was originally designed to predict how much air would be needed for any given dive profile. It was recognized from the outset that the single most important factor besides personal ventilation would be pressure - which increases linearly with depth-since the regulator supplies air at the same pressure as the surrounding water. ${ }^{19}$ With air volumes initially reported at atmospheric pressure, the results were of empirical interest as an indication of cylinder air requirements during particular activities and environmental conditions. It should be noted that the British Sub-Aqua Club encourages its members to measure their own air consumption under controlled conditions, ${ }^{19}$ although the practice remains rather rare, and individual ventilatory response is not a factor usually taken into account in pairing up divers. Scientific dives are usually done under tighter guidelines aimed at achieving an efficient use of air. Even then, the pairing up of divers within a larger group is simply modified in response to changing conditions, as the safety diver signals the two working divers lowest on air to buddy up and head for the surface. ${ }^{2021}$ The experimental procedure developed by the author enabled him to make reasonably accurate predictions of his air consumption at different levels of activity. The procedure as presented here is demanding, but other sport divers may find it interesting to carry out their own streamlined version of this procedure and repeat it once every couple of years.

The second step in the analysis was to remove the dominant but predictable effect of pressure associated with Boyle's law by adjusting the volumes of air to ambient pressure. The results are reported in this way because the phenomenon of $\dot{V}_{E}$ changes induced by pressure and temperature changes is of considerable physiological interest and potential practical importance. Valuable information about the separate effects of temperature, pressure, gas density, and exercise has already been gained from controlled experiments in hyperbaric wet chambers. ${ }^{5-715-17}$ The great difficulty in applying such information to real diving conditions ${ }^{17}$ nevertheless underscores the importance of undertaking field experiments. Ultimately, the usefulness of a predictive formula such as equation 1 should be judged according to two criteria: (1) how well can the personal coefficients $\mathrm{A}, \mathrm{B}$, and $\mathrm{n}$ account for some physiological variability between subjects?; and (2) do these coefficients-as derived by regression analysis-always assume values that seem physiologically reasonable, for example positive and of the same order of magnitude as suggested in the present work? Until then, equation 1 should be seen only as a convenient means to summarize the present data and to assist in interpretation.

It is unclear why $P$ should influence $\dot{V}_{E}$ at the moderate pressures used here, and it is worth stressing that the effect recorded in this (Figure 1) and other studies $^{3-715}$ is relatively small. Indeed, Lanphier and Camporesi ${ }^{17}$ showed that, unless other factors intervene, ${ }^{2} \dot{V}_{\mathrm{E}}$ should remain much the same over a wide range of ambient pressures. The first indication that this may not be strictly true came with a report ${ }^{3}$ that both $\dot{\mathrm{V}}_{2}$ and $\dot{\mathrm{V}}_{\mathrm{E}}$ correlated positively with $\mathrm{P}$. The increase in $\dot{V}_{\mathrm{E}}$ at pressure was tentatively interpreted, in the absence of a thermal balance study, as a manifestation of the increased convective heat loss caused by the increased gas density. ${ }^{11-13}$ In contrast, Gelfand et al ${ }^{4}$ reported a more complex pattern of change of $\dot{V}_{E}$ with $P$. Their findings suggest that increased respiratory flow resistance may have been a major factor over the pressure range 1-4 ATA characteristic of the present experiment. One common denominator in all previous investigations of the pressure effects on $\dot{\mathrm{V}}_{\mathrm{E}}{ }^{46-7}$ is the regulation of water temperature in the range $25-35^{\circ} \mathrm{C}$. This environmentally unrealistic temperature range, together with a very sparse pressure coverage, offers little scope for useful comparisons to be made with the data described here.

The enhancement of $\dot{V}_{E}$ in response to cold-gasinduced core cooling is well documented. ${ }^{11-13}$ In the 
present study, it is clear that the diver also exchanged heat through his wetsuit, ${ }^{914}$ so that the observed response at low temperature was probably also the result of a thermogenic increase in metabolism related to hypothermia. ${ }^{10}$ Although the separation between respiratory heat loss and heat transfer from skin to water is indeterminate in my study, there is no doubt that the latter mechanism must have contributed to the $\dot{\mathrm{V}}_{\mathrm{E}}$ response.

The ambient water temperature was the only temperature related factor that could be measured given the realistic nature of the dives. Nevertheless, $\dot{V}_{E}$ may be more directly related to skin $\left(T_{s}\right)$ and core $\left(T_{c}\right)$ temperature. ${ }^{1222-24}$ Upon immersion in cold water, the former typically shows a rapid ( $\sim 5 \mathrm{~min}$ ) initial drop to an almost constant level, while the latter shows little change during the first $20 \mathrm{~min}$ of immersion, followed by a steady rate of decrease. ${ }^{2224}$ The expected time dependence of $\dot{V}_{E}$ to cooling, although not addressed here, is likely to have been minimized by the $\sim 5 \mathrm{~min}$ delay between the time the diver entered the water and the time the dive was initiated (see Methods).

A plot of $\dot{V}_{E}$ versus $T$ at constant $P$ shows an inflexion point whose exact position (between $6^{\circ} \mathrm{C}$ and $12{ }^{\circ} \mathrm{C}$ ) cannot be established precisely if treated as a fourth adjustable parameter in the curve fitting procedure, although a choice of $\mathrm{T}=8^{\circ} \mathrm{C}$ (equation 1) does minimize the sum of the squares of the residuals. One consequence is that the sensitivity $\delta \dot{\mathrm{V}}_{\mathrm{E}} / \delta \mathrm{T}$ is a broad bell shaped curve, very similar to that representing the sensitivity of cutaneous cold receptors to steady state thermal stimuli. ${ }^{23}$ Since the neural output of these receptors reaches a maximum at $25{ }^{\circ} \mathrm{C}$, the similarity would imply a skin temperature of approximately $25^{\circ} \mathrm{C}$ at $\mathrm{T}=8^{\circ} \mathrm{C}$.

The author is not aware of any wet-stimulation or field studies on the combined effect of $\mathrm{P}$ and $\mathrm{T}$ on $\dot{\mathrm{V}}_{\mathrm{E}}$. The results presented here provide evidence of a reduced response to cold when pressure is raised from 1 to 4 ATA, if only at minimal work rate (Figure 1), and hence of an interaction between the explanatory variables $\mathrm{P}$ and $\mathrm{T}$. The reduced response is unlikely to be caused by increased air density, ${ }^{\circ}$ given that it is not observed under conditions of moderate work rate, that is, of generally higher $\dot{V}_{\mathrm{E}}$ values. The absence of any detectable interaction during exercise allows us to advance the hypothesis that at low levels of physical activity, $\mathrm{P}$-or some covarying variable-tends to counteract the metabolic stimulus of cold. In seeking a definite explanation - which the author cannot, at present offer-it may be worth noting that $\dot{V}_{E}$ is more sensitive to the relative than to the absolute change in pressure (Figure 1).

As the present study illustrates, our ability to study the ventilatory response of $\dot{V}_{E}$ to $P$ and $T$ in the field is limited by the fact that only one data point is extracted from each dive. This approach as presented is quite demanding. Second generation dive computers which monitor $\dot{V}_{E}$ during the course of a single dive are being developed. ${ }^{25}$ They offer the possibility of streamlining the experimental scheme presented here, for example by conducting seasonal experiments whereby the pressure dependence of $\dot{V}_{E}$ is recorded on several subjects in the course of only one dive. Once a ventilatory response applicable to the general diving population has been established, further experimentation (nature of breathing gas, role of pressure versus gas density, etc) may lead to a reformulation of $\dot{V}_{E}(P, T)$ based on explicit physiological processes rather than empirical correlations.

\section{Acknowledgements}

The author is indebted to Dr Elizabeth Cook (Jefferson Medical School, Philadelphia, PA 19107, USA) and to Mr Jerry Prezioso (National Marine Fisheries Service, Narragansett, RI 02882, USA) for their participation in the dives which formed the basis of this experiment.

\section{References}

1 Šmejkal V, Vávra J, Bartáková L, Kryl L, Paleček F. The pattern of breathing and the ventilatory response to breathing through a tube and to physical exercise in sport divers. Eur J Appl Physiol 1989; 59: 55-8.

2 Ellingsen $I$. The influence of the breathing pattern in man of moderate levels of continuous positive and negative airway pressure and of positive end-expiratory pressure during air and $\mathrm{CO}_{2}$ inhalation. Acta Physiol Scand 1990; 138: 273-82.

3 Saltzman HA, Salzano JV, Blenkarn GD, Kylstra JA. Effects of pressure on ventilation and gas exchange in man. J Appl Physiol $1971 ; 4$ : 443-49.

4 Gelfand R, Lambertsen CJ, Strauss R, Clark JM, Puglia CD. Human respiration at rest in rapid compression and at high pressures and gas densities. J Appl Physiol 1983; 54: 290-303.

5 Norfleet WT, Hickey DD, Lundgren CEG. A comparison of respiratory function in divers breathing with a mouthpiece or a full face mask. Undersea Biomed Res 1987; 14: 503-26.

6 Hickey DD, Norfleet WT, Pảsche AJ, Lundgren CEG. Respiratory function in the upright working diver at 6.8 ATA. Undersea Biomed Res 1987; 14: 241-62.

7 Taylor NAS, Morrison JB. Effects of breathing-gas pressure on pulmonary function and work capacity during immersion. Undersea Biomed Res 1990; 17: 413-28.

8 Stang PR, Wiener EL. Diver performance in cold water. Human Factors 1970; 12: 391-99.

9 Wolff AH, Coleshaw SRK, Newstead CG, Keatinge WR. Heat exchanges in wet suits. J Appl Physiol 1985; 58: 770-77.

10 Choukroun M-L, Kays C, Varène P. Effects of water temperature on pulmonary volumes in immersed human subjects. Respir Physiol $1989 ; 75: 255-66$.

11 Guenard $\mathrm{H}$, Timbal J, Varène $\mathrm{P}$, Viellefond $\mathrm{H}$. La déperdition thermique par convection respiratoire en plongée profounde. In: Hesser CM, Linnarsson D, eds. Proceedings of the first annual scientific meeting of the European Undersea Biomedical Society 1973; 9: $475-80$.

12 Piantadosi CA, Thalmann ED, Spaur WH. Metabolic response to respiratory heat loss-induced core cooling. J Appl Physiol 1981; 50 : 829-34.

13 Burnet H, Lucciano $M$, Jammes $Y$. Respiratory effects of cold-gas breathing in humans under hyperbaric environment. Respir Physiol $1990 ; 81$ : 413-24.

14 Webb W. Thermal problems. In: Bennett PB, Elliott DH, eds. The physiology and medicine of diving. San Pedro: Best Publishing, 1982: 297-318.

15 Lundgren CEG. Respiratory function during simulated wet dives. Undersea Biomed Res 1984; 11 : 139-47.

16 Morrison JB, Taylor NAS. Measurement of static and dynamic pulmonary work during pressure breathing. Undersea Biomed Res 1990; 17: 453-67.

17 Lanphier EH, Camporesi EM. Respiration and exercise. In: Bennett PB, Elliott DH, eds. The physiology and medicine of diving. San Pedro: Best Publishing, 1982: 99-156.

18 Walpole RE, Myers RH. Probability and statistics for scientists and engineers. New York: Macmillan, 1985: 471-501.

19 BSAC. The air supply. In: Busuttili M, Holbrook M, Ridley G, Todd M, eds. Sport diving: the British Sub-Aqua Club diving manual. Musselburgh: Scotprint Ltd, 1992: 115-18. 
20 Coale K, Michaels A, Pinto R. Blue water diving equipment and procedures. In: Heine JN, ed. Blue water diving guidelines. La Jolla: California Sea Grant College Program, 1986: 28-42.

21 McLoughlin R, Kirkman H, CSIRO Diving procedures manual. CSIRO Marine Laboratories Report 201, 1989: 20.

22 Hayward JS, Eckerson JD, Collis ML. Thermoregulatory heat production in man: prediction equation based on skin and core temperature. J Appl Physiol 1977; 42: 377-84.
23 Mekjavic IB, Morrison JB. Evaluation of predictive formulae for determining metabolic rate during cold water immersion. Aviat Space Environ Med 1986; 57: 671-80.

24 Hayward JS, French CD. Hyperventilation response to cold water immersion: reduction by stage entry. Aviat Space Environ Med 1989; 60: 1163-65.

25 Bantin J. A critical review of the features present in the Suunto EON dive computer. Diver 1994; 39: 68-9.

\section{BASM Merchandise 1995}

Ladies scarves

Ties

Blazer badge
White with blue border and BASM logo - 27-inch square Navy blue with fringe and BASM logo $54 \times 9$ inches (oblong)

Single motif

Multi motif

Wire -4 inches high

Wire -3 inches high

$$
\begin{aligned}
& £ 5+£ 1 p \& p \\
& £ 5+£ 1 p \& p \\
& £ 6+£ 1 p \& p \\
& £ 6+£ 1 p \& p \\
& £ 5+£ 1 p \& p \\
& £ 5+£ 1 p \& p
\end{aligned}
$$

New stock to order

Sweaters

Slipovers

Sweatshirts

Polo shirts
Lambswool fine knit, V-neck or round neck with small motif. Machine washable. State colour and chest size required.

Lambswool fine knit, V-neck, with small motif. Machine washable. State colour and chest size required.

With small motif.

State colour and chest size required.

With small motif.

State colour and chest size required 